\title{
Convexity subarachnoid hemorrhage in lobar intracerebral hemorrhage
}

\section{A prognostic marker}

Nicolas Raposo, MD, Andreas Charidimou, MD, PhD, Duangnapa Roongpiboonsopit, MD, MSc, Michelle Onyekaba, MBBS, M. Edip Gurol, MD, Jonathan Rosand, MD, MSc, Steven M. Greenberg, MD, PhD, Joshua N. Goldstein, MD, PhD, and Anand Viswanathan, MD, PhD

Neurology ${ }^{\circledR}$ 2020;94:e968-e977. doi:10.1212/WNL.0000000000009036

\section{Abstract}

\section{Objective}

To investigate whether acute convexity subarachnoid hemorrhage (cSAH) associated with acute lobar intracerebral hemorrhage $(\mathrm{ICH})$ increases the risk of $\mathrm{ICH}$ recurrence in patients with cerebral amyloid angiopathy (CAA).

\section{Methods}

We analyzed data from a prospective cohort of consecutive survivors of acute spontaneous lobar ICH fulfilling the Boston criteria for possible or probable CAA (CAA-ICH). We analyzed baseline clinical and MRI data, including cSAH (categorized as adjacent or remote from ICH on a standardized scale), cortical superficial siderosis (cSS), and other CAA MRI markers. Multivariable Cox regression models were used to assess the association between cSAH and recurrent symptomatic ICH during follow-up.

\section{Results}

We included 261 CAA-ICH survivors (mean age $76.2 \pm 8.7$ years). Of them, 166 (63.6\%, 95\% confidence interval [CI] 57.7\%-69.5\%) had cSAH on baseline MRI. During a median follow-up of 28.3 (interquartile range 7.2-57.0) months, 54 (20.7\%) patients experienced a recurrent lobar ICH. In Cox regression, any cSAH, adjacent cSAH, and remote cSAH were independent predictors of recurrent $\mathrm{ICH}$ after adjustment for other confounders, including cSS. Incidence rate of recurrent ICH in patients with cSAH was 9.9 per 100 person-years (95\% CI 7.3-13.0) compared with 1.2 per 100 person-years (95\% CI 0.3-3.2) in those without cSAH (adjusted hazard ratio 7.5 , 95\% CI 2.6-21.1).

\section{Conclusion}

In patients with CAA-related acute $\mathrm{ICH}$, cSAH (adjacent or remote from lobar ICH) is commonly observed and heralds an increased risk of recurrent ICH. cSAH may help stratify bleeding risk and should be assessed along with cSS for prognosis and clinical management.

\author{
Correspondence \\ Dr. Raposo \\ raposo.n@chu-toulouse.fr
}

\section{RELATED ARTICLE}

\section{Editorial}

To predict recurrence in cerebral amyloid angiopathy, look to the subarachnoid space

Page 375

\footnotetext{
From the Stroke Research Center (N.R., A.C., D.R., M.O., M.E.G., J.R., S.M.G., J.N.G., A.V.), Department of Neurology, Division of Neurocritical Care and Emergency Neurology (J.R., J.N.G.), Center for Genomic Medicine (J.R.), and Henry and Allison McCance Center for Brain Health (J.R.), Massachusetts General Hospital, Harvard Medical School, Boston; Department of Neurology (N.R.), Hôpital Pierre-Paul Riquet, Centre Hospitalier Universitaire de Toulouse; Toulouse Neurolmaging Center (N.R.), Université de Toulouse, Inserm, UPS, France; and Division of Neurology (D.R.), Faculty of Medicine, Department of Medicine, Naresuan University, Phitsanulok, Thailand.

Go to Neurology.org/N for full disclosures. Funding information and disclosures deemed relevant by the authors, if any, are provided at the end of the article.
} 


\section{Glossary}

ATACH-2 = Antihypertensive Treatment of Acute Cerebral Hemorrhage 2; CAA = cerebral amyloid angiopathy; CI = confidence interval; $\mathbf{C M B}=$ cerebral microbleed; $\mathbf{c S A H}=$ subarachnoid hemorrhage; $\mathbf{c S S}=$ cortical superficial siderosis; FLAIR = fluid-attenuated inversion recovery; GRE = gradient recalled echo; ICH = intracerebral hemorrhage; INTERACTII = Intensive Blood Pressure Reduction in Acute Cerebral Hemorrhage Trial-II; IQR = interquartile range; IVH = intraventricular hemorrhage; SVD = small vessel disease; SWI = susceptibility-weighted imaging; WMH = white matter hyperintensities.

Cerebral amyloid angiopathy (CAA) is the most important cause of lobar intracerebral hemorrhage (ICH) in the elderly, ${ }^{1}$ a devastating disease characterized by high mortality rate, ${ }^{2}$ poor functional outcome, ${ }^{3}$ and dementia. ${ }^{4,5}$ Despite preventive strategies, including tight blood pressure control $^{6}$ and bleeding risk-based anticoagulant strategy, ${ }^{7}$ the risk of recurrent $\mathrm{ICH}$ is high in patients with CAA-related ICH (CAA-ICH) ${ }^{8}$ However, future ICH risk appears heterogeneous in patients with $\mathrm{CAA},{ }^{9-11}$ and accurately stratifying this risk may guide clinical management of these patients.

Convexity subarachnoid hemorrhage $(\mathrm{cSAH})$ is sometimes observed simultaneously with lobar $\mathrm{ICH}^{12}$ and was thought to result from extension to a parenchymal hemorrhage into the subarachnoid space. Recently, the presence of cSAH associated with lobar ICH has been linked to underlying CAA, ${ }^{13,14}$ raising the possibility that $\mathrm{CSAH}$ may be caused by the rupture of leptomeningeal vessels, affected predominantly in CAA. ${ }^{15}$ Hence, cSAH might be a marker of vascular fragility, especially because cortical superficial siderosis (cSS), the chronic form of superficial bleeding in CAA resulting from episodes of acute $\mathrm{cSAH}$, is a major risk factor for future ICH. ${ }^{9,10,16-19}$ Whether cSAH heralds an increased risk of recurrent $\mathrm{ICH}$ in patients with CAA-ICH remains unknown.

In this prospective cohort study, we aimed to determine the prognostic relevance of cSAH in patients with CAA$\mathrm{ICH}$. We investigated whether $\mathrm{cSAH}$ associated with acute lobar ICH is a predictor of ICH recurrence in patients with CAA.

\section{Methods}

\section{Study design}

We used data from an established prospective observational cohort study of consecutive survivors of lobar ICH admitted to the Massachusetts General Hospital, Boston, between February 1997 and October 2014.

\section{Standard protocol approvals, registrations, and patient consents}

This study was performed with approval of the institutional review board of Massachusetts General Hospital with informed consent from all participants or family members.

\section{Study population}

Participants were consecutive ICH survivors drawn from an ongoing longitudinal cohort study of spontaneous lobar ICH who had MRI, as previously described in detail. ${ }^{20}$ For the present study, our inclusion criteria were (1) acute symptomatic lobar ICH in patients who were alive at discharge; (2) diagnosis of definite, probable, or possible CAA based on the original Boston criteria ${ }^{21}$ (i.e., including lobar cerebral microbleeds [CMBs] but not including cSS in the diagnostic criteria); (3) MRI with fluid-attenuated inversion recovery (FLAIR) and blood-sensitive sequences of adequate quality performed within 10 days after symptom onset; and (4) available follow-up information on symptomatic $\mathrm{ICH}$, confirmed by neuroimaging. We excluded patients with history of head injury and those who underwent brain surgery before MRI to avoid other potential causes of cSAH.

\section{Baseline data collection}

Demographic information and baseline clinical data (vascular risk factors, history of $\mathrm{ICH}$, cardiovascular event, medication use) were prospectively collected, as previously described. ${ }^{20}$ Hypertension was defined as the use of any antihypertensive medication or documented elevated blood pressure $>140$ / $90 \mathrm{~mm} \mathrm{Hg}$ before admission. APOE genotype was determined from all patients who donated blood samples for genetic analysis and provided informed consent.

\section{MRI acquisition and analysis}

Images were acquired on a $1.5 \mathrm{~T}$ scanner and included at least $\mathrm{T}^{*}$-weighted gradient recalled echo (T2*-GRE) and FLAIR sequences, as previously detailed. ${ }^{22}$ A small subset of patients $(n=15,5.7 \%)$ underwent susceptibility-weighted imaging (SWI) instead of T2*-GRE as the blood-sensitive sequence. Their baseline clinical and imaging characteristics were not different from those who had T2*-GRE (data not shown).

All MRIs were reviewed by the investigators, who were blinded to the baseline clinical data and follow-up information, according to the Standards for Reporting Vascular Changes on Neuroimaging. ${ }^{23}$ Lobar ICH was defined as intraparenchymal hemorrhage involving the cerebral cortex and underlying subcortical white matter without extending into deep brain regions (e.g., basal ganglia, thalamus). ICH volume on baseline CT was calculated by investigators blinded to MRI with semiautomated planimetric methods (Alice; PAREXEL International Corp, Waltham, MA; and Analyze 10.0; Mayo Clinic, Rochester, MN). 
cSAH and cSS were independently assessed by 2 trained investigators (N.R. and D.R.). A third trained investigator (A.C.) rated a random $20 \%$ sample for $\mathrm{cSAH}$ presence and extent and another $20 \%$ sample for cSS presence and extent. cSAH was defined as linear hyperintense signal on FLAIR (suggestive of acute bleeding) with or without corresponding hypointense signal on $\mathrm{T} 2{ }^{*} \mathrm{GRE}$ (or SWI) in the subarachnoid space that affected $\geq 1$ cortical sulci of the cerebral convexities. ${ }^{18}$ The location and extension (number of sulci) of acute cSAHs were visually assessed. cSAH extent was classified as adjacent to the ICH when the bleeding was strictly (without evidence of cSAH remote from $\mathrm{ICH}$ ) confined to contiguous sulci within 1 to 2 sulci from acute $\mathrm{ICH}$ or as remote from the $\mathrm{ICH}$ when cSAH was observed away from at least 2 unaffected sulci of acute ICH, with or without associated adjacent cSAH (figure $1)$. The interrater reliability was excellent for $\mathrm{CSAH}$ presence $(\kappa$ $=0.80)$ and good for cSAH extent $(\kappa=0.72)$. We carefully differentiated cSAH from cSS, which was defined as linear residues of chronic blood products in the superficial layers of the cerebral cortex that showed a characteristic gyriform hypointense signal pattern on the T2* GRE/SWI images but with no corresponding hyperintense signal on FLAIR images (unlike cSAH). cSS was visually assessed according to the consensus recommended criteria. ${ }^{18}$ We did not include cSS connected to ICH to minimize the risk of misclassification between cSS and acute cSAH. The extent of cSS was classified as focal (restricted to $\leq 3$ sulci) or disseminated ( $\geq 4$ sulci). The interrater agreement was excellent for cSS presence $(\kappa=0.79)$ and good for cSS extent $(\kappa=0.74)$. CMB number and distribution were evaluated on the T2*-GRE or SWIs according to the current consensus criteria. ${ }^{24}$ White matter hyperintensities (WMH) were visually assessed on the axial FLAIR images with the 7-point Fazekas rating scale. ${ }^{25}$

\section{Follow-up}

Follow-up data were obtained from consenting survivors and their caregivers by systematic telephone interview at 6-month intervals after ICH, as previously described. ${ }^{20}$ We collected information on recurrent symptomatic ICH and death after index ICH. All recurrent ICH reports were confirmed by direct review of brain imaging (MRI or CT scan) by a study investigator blinded to baseline clinical and MRI information. We recorded the number and location of recurrent symptomatic ICH. Blood pressure measurements during follow-up were obtained from medical records.

\section{Statistical analysis}

We compared baseline clinical and imaging characteristics between patients with and without $\mathrm{CSAH}$ and between those with and without recurrent symptomatic ICH during follow-up. We used the $\chi 2$ test or the Fisher exact test for categorical variables and the 2-sample $t$ test or Mann-Whitney $U$ test for continuous variables, as appropriate. Multivariable binominal logistic regression was used to determine factors associated with the presence of cSAH. Age and variables with a value of $p<0.05$ in the univariable analysis (previous history of symptomatic $\mathrm{ICH}$,
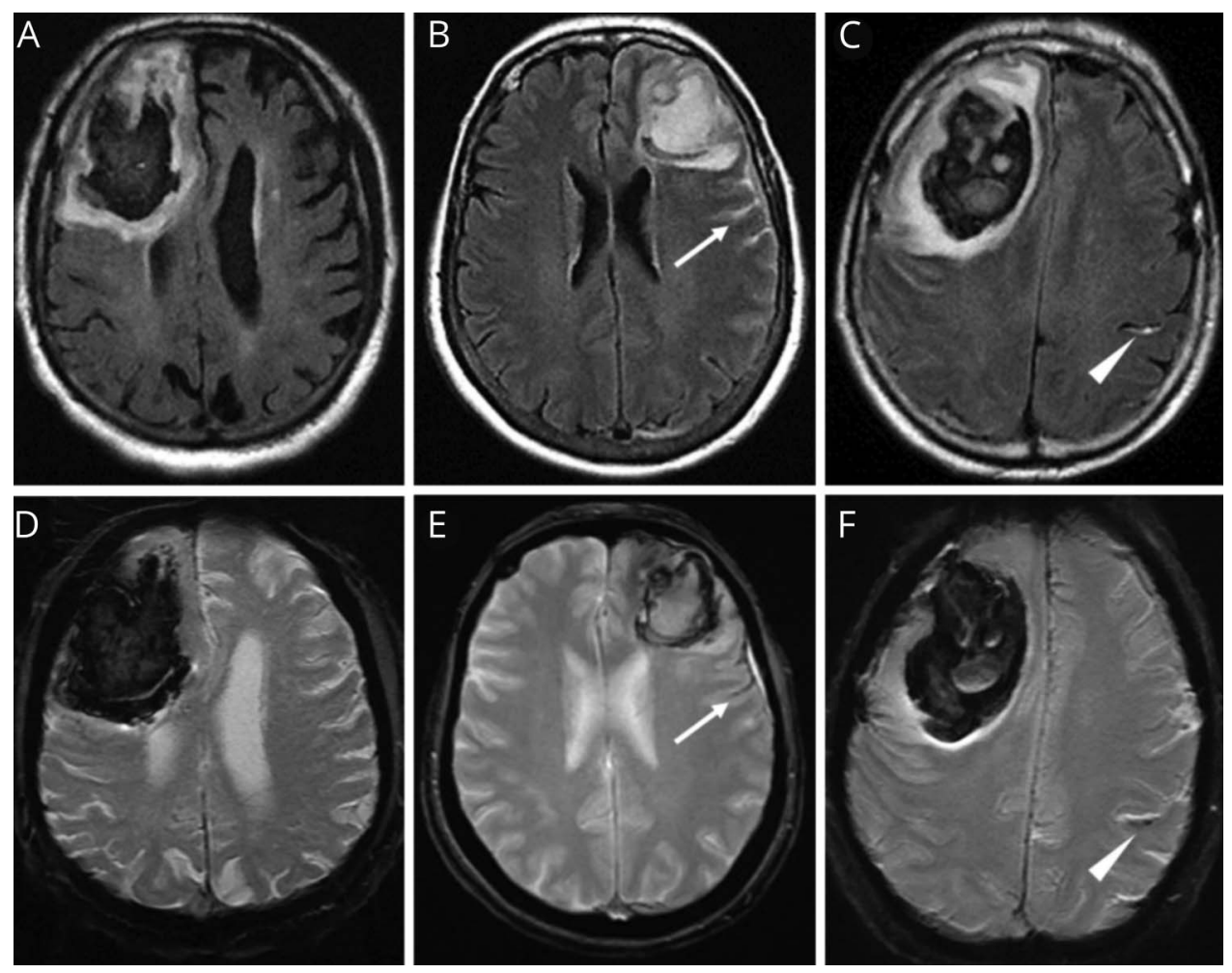

(A-C) Axial fluid-attenuated inversion recovery and (D-F) T2*-gradient recalled echo of 3 cases of cerebral amyloid angiopathy-related acute intracerebral hemorrhage (ICH). (A and D) Patient without convexity subarachnoid hemorrhages (CSAH): acute right frontal ICH without evidence of CSAH. (B and E) Patient with adjacent cSAH: cSAH (white arrow) was observed in 3 sulci adjacent to the acute left frontal ICH. (C and F) Patient with remote $\mathrm{CSAH}$ : $\mathrm{CSAH}$ (white arrowhead) was detected in the left frontal lobe, remote from the acute right frontal $\mathrm{ICH}$. 
i.e., other than index ICH; presence of $A P O E \varepsilon 2$ allele; ICH volume; cSS presence; lobar CMB count) were entered into the model. Multicollinearity was assessed with variance inflation factors, and predictors with a variance inflation factor $>5$ were removed from the model.

We calculated the absolute event rate per 100 person-years for recurrent symptomatic ICH. We determined predictors of a recurrent symptomatic $\mathrm{ICH}$ in univariable analyses using Kaplan-Meier plots with significance testing by the log-rank test. Survival time was calculated from date of discharge at index ICH until the date of recurrent symptomatic ICH at follow-up or the last known date without symptomatic ICH during follow-up. For patients experiencing multiple symptomatic ICH events during follow-up $(n=3)$, data were censored after the first symptomatic ICH event. We determined the presence of $\mathrm{cSAH}$ as a univariable predictor of recurrent $\mathrm{ICH}$. We performed multivariable analyses using Cox regression models to calculate multivariable hazard ratios for recurrent $\mathrm{ICH}$ according to the baseline presence (vs absence) and extent (no cSAH, adjacent cSAH, remote cSAH) of cSAH. We included in multivariable modeling all variables associated with recurrent symptomatic ICH in univariable analysis with a value of $p<0.05$ (previous symptomatic $\mathrm{ICH}$, presence of $\mathrm{cSS}$, cSAH presence or extent) and other potential predisposing factors of ICH recurrence based on prior studies (age, presence of lobar CMB). The proportional hazard assumption was tested with graphical check and Schoenfeld residual-based tests.

A value of $p \leq 0.05$ was considered statistically significant. All analyses were performed with the Statistical Package for the Social Sciences version 24 (for Windows; SPSS Inc, Chicago, IL).

\section{Data availability}

The authors certify they have documented all data, methods, and materials used to conduct the research presented. Anonymized data pertaining to the research presented will be made available by request from qualified investigators.

\section{Results}

Our final cohort consisted of $261 \mathrm{ICH}$ survivors (mean age 76.2 \pm 8.7 years, $52 \%$ female) with suspected CAA: 11 with pathologically proven CAA, 142 with probable CAA, and 108 with possible CAA. A flow diagram of the participants is shown in figure 2. The median time from symptom onset to MRI was 2 days (interquartile range $[\mathrm{IQR}] 1-3$ days). The median length of stay for the patients with ICH was 7 days (IQR 4-10 days).

Figure 2 Flow diagram

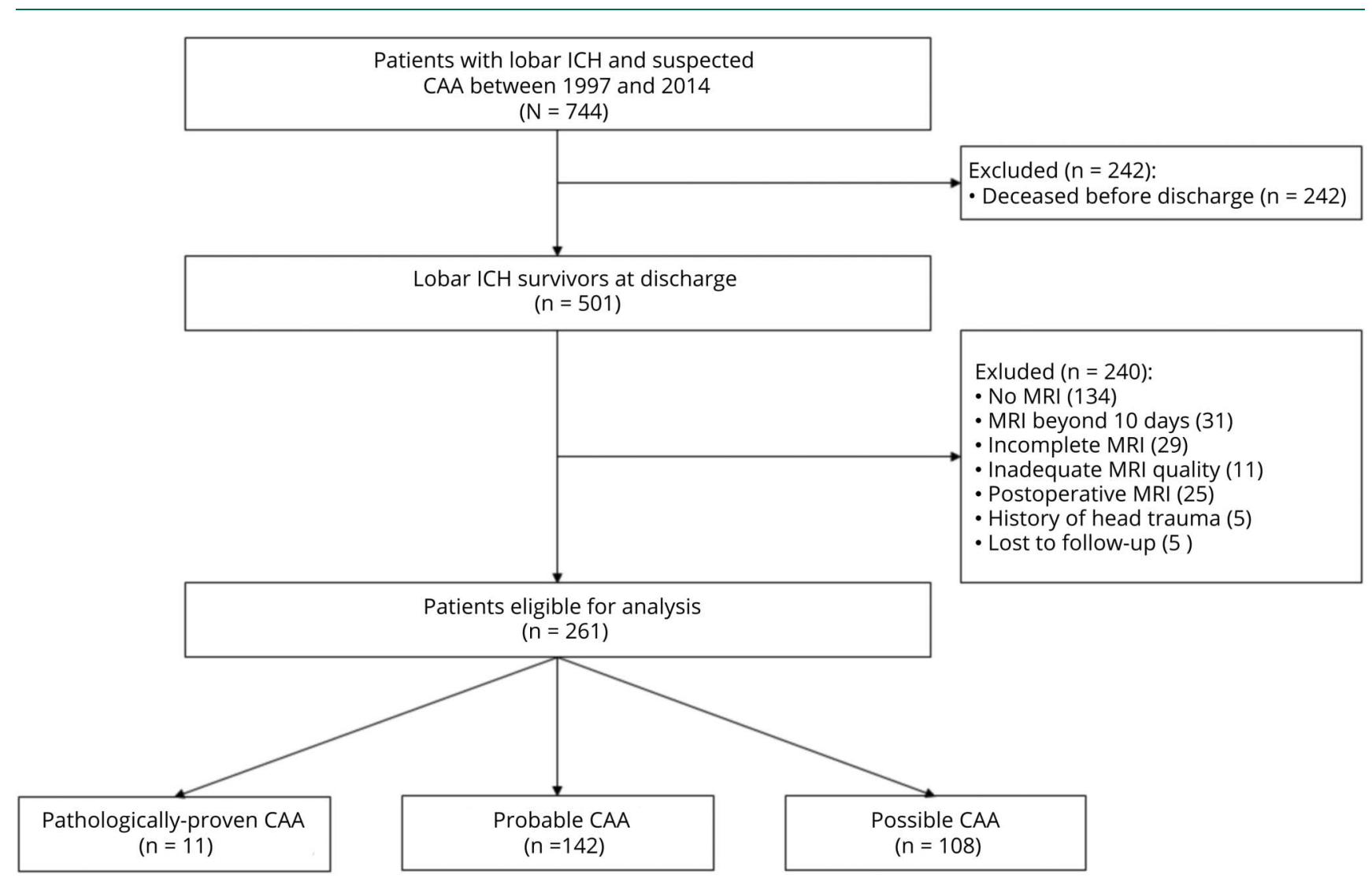

CAA = cerebral amyloid angiopathy; ICH = intracerebral hemorrhage. 


\section{Prevalence of cSAH and associated factors}

cSAH was present in 166 of 261 patients (64\%, 95\% confidence interval [CI] 58\%-70\%) on baseline MRI and was more frequently observed in patients with pathologically proven or probable CAA than in those with possible CAA ( $77.8 \%$ vs $43.5 \%$; $p<0.001)$. Of 166 patients with cSAH, 98 (59\%) had cSAH adjacent to acute lobar $\mathrm{ICH}$, and 68 (41\%) had cSAH remote from $\mathrm{ICH}$, with a median number of 3 (IQR 2-6) affected sulci. Compared to patients without $\mathrm{cSAH}$ at baseline, patients with $\mathrm{cSAH}$ had larger ICH volume and were more likely to have a history of ICH (before index ICH), APOE $\varepsilon 2$ allele, cSS, and higher lobar CMB count (table 1). In the multivariable analysis, presence of cSS was the only factor independently associated with cSAH (odds ratio 4.42, 95\% CI 1.15-17.08; $p=0.03$ ).

\section{cSAH and risk of recurrent ICH}

During a median follow-up of 28.3 months (IQR 7.2-57.0 months), 54 (20.7\%) patients experienced recurrent symptomatic ICH. Of them, 3 had multiple $(>1)$ recurrent ICHs. The median delay from baseline ICH to the first recurrent ICH was 19.5 months (IQR 2.4-44.5 months). All recurrent ICHs were lobar, and 27 (50\%) patients had recurrent ICH in the same hemisphere as the baseline ICH. Compared to those who did not experience recurrent $\mathrm{ICH}$, patients with recurrent ICH during follow-up had a higher prevalence of previous ICH (other than index ICH) and were more likely to have cSAH and cSS (table 2).

The incidence rate of recurrent symptomatic ICH in patients with cSAH was 9.9 per 100 person-years (95\% CI 7.3-13.0) compared to 1.2 per 100 person-years (95\% CI

Table 1 Baseline characteristics of CAA-related ICH survivors: Comparison between patients with and without CSAH

\begin{tabular}{|c|c|c|c|c|}
\hline & Whole ICH cohort & Patients with cSAH & Patients without cSAH & $p$ Value \\
\hline No. & 261 & 166 & 95 & \\
\hline \multicolumn{5}{|l|}{ Demographics } \\
\hline Age, mean $\pm S D, y$ & $76.2 \pm 8.7$ & $75.6 \pm 8.1$ & $77.3 \pm 9.5$ & 0.236 \\
\hline Female, n (\%) & $137(52.5)$ & $92(55.4)$ & $45(47.4)$ & 0.21 \\
\hline \multicolumn{5}{|l|}{ Clinical characteristics } \\
\hline Hypertension, n (\%) & $167(64.0)$ & $104(62.7)$ & $63(66.3)$ & 0.553 \\
\hline Previous symptomatic ICH, n (\%) & $24(9.2)$ & $21(12.7)$ & $4(4.2)$ & 0.026 \\
\hline Atrial fibrillation, n (\%) & $42(16.1)$ & $23(13.9)$ & $19(20.0)$ & 0.194 \\
\hline Warfarin use, n (\%) & $30(11.5)$ & $15(9.0)$ & $15(15.8)$ & 0.1 \\
\hline Antiplatelet use, n (\%) & $107(41.0)$ & $69(41.6)$ & $38(40.0)$ & 0.804 \\
\hline Statin use, $\mathbf{n}(\%)$ & $83(31.8)$ & $49(29.5)$ & $34(35.8)$ & 0.295 \\
\hline APOE $\varepsilon 2$ ( $\geq 1$ copy), ${ }^{a}$ n. (\%) & $27(18.5)$ & $22(23.4)$ & $5(9.6)$ & 0.04 \\
\hline APOE $\varepsilon 4$ ( $\geq 1$ copy), ${ }^{a} n(\%)$ & $50(34.2)$ & $32(34.0)$ & $18(34.6)$ & 0.944 \\
\hline \multicolumn{5}{|l|}{ Imaging characteristics } \\
\hline Onset to MRI, median (IQR), d & $2(1-3)$ & $2(1-3)$ & $2(1-3)$ & 0.732 \\
\hline ICH volume, median (IQR), mL & $20.0(9.2-35.4)$ & $22.1(11.6-36.1)$ & $14.0(5.3-28.5)$ & 0.001 \\
\hline Presence of IVH, n (\%) & $55(21.1)$ & $35(21.1)$ & $20(21.1)$ & 0.995 \\
\hline Presence of cSS, n (\%) & $57(21.8)$ & $49(29.5)$ & $8(8.4)$ & $<0.001$ \\
\hline Focal cSS, n (\%) & $30(11.5)$ & $28(16.9)$ & $2(2.1)$ & $<0.001$ \\
\hline Disseminated cSS, n (\%) & $27(10.3)$ & $21(12.7)$ & $6(6.3)$ & 0.106 \\
\hline Presence of lobar CMB, n (\%) & $146(55.9)$ & $112(67.5)$ & $34(35.8)$ & $<0.001$ \\
\hline Lobar CMB count, median (IQR), n & $1(0-3)$ & $2(0-4)$ & $0(0-2)$ & $<0.001$ \\
\hline Fazekas WMH score, median (IQR) & $4(3-5)$ & $4(3-5)$ & $4(2-5)$ & 0.48 \\
\hline
\end{tabular}

Abbreviations: $\mathrm{CAA}=$ cerebral amyloid angiopathy; $\mathrm{CMB}=$ cerebral microbleed; $\mathrm{CSAH}=$ subarachnoid hemorrhage; $\mathrm{cSS}=$ cortical superficial siderosis; $\mathrm{ICH}=$ intracerebral hemorrhage; IQR = interquartile range; IVH = intraventricular hemorrhage; $\mathrm{WMH}$ = white matter hyperintensities.

a One hundred forty-six patients consented for $A P O E$ genotype testing. 
Table 2 Characteristics of patients with vs without ICH recurrence during follow-up

\begin{tabular}{|c|c|c|c|}
\hline & Patients with recurrent ICH $(n=54)$ & Patients without recurrent ICH $(n=207)$ & $p$ Value \\
\hline \multicolumn{4}{|l|}{ Demographics } \\
\hline Age, mean $\pm S D, y$ & $75.7 \pm 7.6$ & $76.4 \pm 9.0$ & 0.874 \\
\hline Female, n (\%) & 30 (55.6) & $107(51.7)$ & 0.613 \\
\hline \multicolumn{4}{|l|}{ Baseline clinical characteristics } \\
\hline Hypertension, n (\%) & $27(50.0)$ & $140(67.6)$ & 0.016 \\
\hline Previous symptomatic ICH, n (\%) & 10 (18.5) & $14(6.8)$ & 0.008 \\
\hline APOE $\varepsilon 2$ ( $\geq 1$ copy), ${ }^{a} n(\%)$ & $10(23.8)$ & $17(16.3)$ & 0.293 \\
\hline$A P O E \varepsilon 4$ ( $\geq 1$ copy), ${ }^{a} n(\%)$ & $11(26.2)$ & $39(37.5)$ & 0.192 \\
\hline \multicolumn{4}{|l|}{ Baseline imaging characteristics } \\
\hline Baseline ICH volume, median (IQR), mL & $24.6(10.1-36.1)$ & $18.3(9.1-35.0)$ & 0.228 \\
\hline IVH presence, $\mathrm{n}(\%)$ & $10(18.5)$ & $45(21.7)$ & 0.605 \\
\hline Presence of cSAH, $n(\%)$ & $50(92.6)$ & $116(56.0)$ & $<0.001$ \\
\hline cSAH adjacent to ICH, n (\%) & $31(57.4)$ & $67(32.4)$ & 0.001 \\
\hline cSAH remote from ICH, $n(\%)$ & 19 (35.2) & $49(23.7)$ & 0.086 \\
\hline Presence of cSS, n (\%) & 19 (35.2) & $38(18.4)$ & 0.008 \\
\hline Presence of lobar CMBs, $\mathbf{n}(\%)$ & $34(63.0)$ & $112(54.1)$ & 0.243 \\
\hline Multiple lobar CMBs (>2), n (\%) & $25(46.3)$ & $91(44.0)$ & 0.758 \\
\hline Severe (Fazekas score 5-6) WMH, n (\%) & $16(29.6)$ & $69(33.3)$ & 0.605 \\
\hline \multicolumn{4}{|l|}{ Blood pressure during follow-up } \\
\hline $\mathrm{SBP}^{\mathrm{b}}$ mean $\pm \mathrm{SD}, \mathrm{mm} \mathrm{Hg}$ & $135.5 \pm 11.0$ & $134.2 \pm 11.3$ & 0.509 \\
\hline $\mathrm{DBP},{ }^{\mathrm{b}}$ mean $\pm \mathrm{SD}, \mathrm{mm} \mathrm{Hg}$ & $75.6 \pm 7.4$ & $75.5 \pm 7.1$ & 0.949 \\
\hline \multicolumn{4}{|c|}{$\begin{array}{l}\text { Abbreviations: } \mathrm{CMB}=\text { cerebral microbleed; } \mathrm{CSAH}=\text { subarachnoid hemorrhage; } \mathrm{cSS}=\text { cortical superficial siderosis; } \mathrm{DBP}=\text { diastolic blood pressure; ICH = } \\
\text { intracerebral hemorrhage; IQR = interquartile range; IVH = intraventricular hemorrhage; } \mathrm{SBP}=\text { systolic blood pressure; WMH = white matter hyperintensities. } \\
\text { a One hundred forty-six patients consented for } A P O E \text { genotype testing. } \\
\text { b } \text { Missing, } \mathrm{n}=30 \text { (blood pressure measurements during follow-up not available). }\end{array}$} \\
\hline
\end{tabular}

0.3-3.2) in those without cSAH (table 3). In Kaplan-Meier analysis, the presence of $\mathrm{cSAH}$ was a predictor for $\mathrm{ICH}$ recurrence (log-rank $p<0.0001$; figure 3 ). Compared to no cSAH, both adjacent SAH $(p<0.0001)$ and remote cSAH $(p<0.0001)$ were associated with an increased risk of recurrent ICH. Patients with remote $\mathrm{cSAH}$ from ICH did not have an increased risk of recurrent ICH compared to those with adjacent $c S A H(p=0.957)$. The other univariable predictors of recurrent $\mathrm{ICH}$ were history of $\mathrm{ICH}$ and cSS presence.

In multivariable Cox regression analysis, presence of cSAH (hazard ratio 7.5, 95\% CI 2.6-21.1, $p<0.001$ ) was an independent predictor of recurrent symptomatic ICH (table 4). In multivariable Cox regression model including cSAH extent, both adjacent $\mathrm{cSAH}$ and remote $\mathrm{cSAH}$ were predictors of recurrent ICH. These results remained consistent after adjustment for CAA diagnostic category (i.e., pathologically proven or probable CAA vs possible CAA).
In a subgroup analysis restricted to participants with pathologically proven or probable CAA $(n=153)$, the incidence rate of recurrent symptomatic $\mathrm{ICH}$ in patients with $\mathrm{CSAH}$ was 9.7 per 100 person-years (95\% CI 6.8-13.4) compared to 3.7 per 100 person-years (95\% CI 1.0-9.5) in those without cSAH ( $p=0.074$; table 3$)$. Among patients with possible CAA $(\mathrm{n}=108)$, the incidence rate of recurrent symptomatic ICH in patients with cSAH was 10.2 per 100 person-years (95\% CI 5.6-17.1) compared to 0 per 100 person-years in those without $\mathrm{cSAH}(p=0.042)$.

\section{Discussion}

In this prospective cohort study of CAA-ICH survivors, acute cSAH associated with lobar ICH was detected with MRI in $>60 \%$ of patients within 10 days after symptom onset and was associated with an increased risk of recurrent symptomatic $\mathrm{ICH}$, independently of cSS. cSAH adjacent to acute ICH 
Table 3 Event rate and univariable and multivariable hazard ratio for recurrent symptomatic ICH during follow-up according to presence and extent of CSAH at baseline

\begin{tabular}{|c|c|c|c|c|c|}
\hline & \multicolumn{5}{|c|}{ Recurrent symptomatic ICH } \\
\hline & Events, $\mathbf{n}$ & Person-years & $\begin{array}{l}\text { Rate per } 100 \text { person-y } \\
(95 \% \mathrm{CI})\end{array}$ & $\begin{array}{l}\text { Unadjusted } \\
\text { HR }(95 \% \mathrm{Cl})\end{array}$ & $\begin{array}{l}\text { Adjusted }^{\mathrm{a}} \\
\text { HR }(95 \% \mathrm{Cl})\end{array}$ \\
\hline \multicolumn{6}{|l|}{ Whole ICH cohort $(n=261)$} \\
\hline cSAH absent & 4 & 319 & $1.2(0.3-3.2)$ & 1 (Ref) & 1 (Ref) \\
\hline cSAH present & 50 & 508 & $9.9(7.3-13.0)$ & $7.5(2.7-20.8)$ & $7.5(2.6-21.1)$ \\
\hline cSAH adjacent to ICH & 31 & 313 & $9.9(6.7-14.0)$ & $7.6(2.7-21.4)$ & $7.9(2.7-22.9)$ \\
\hline cSAH remote from ICH & 19 & 194 & $9.8(5.9-15.3)$ & $7.4(2.5-21.9)$ & $6.9(2.3-20.8)$ \\
\hline \multicolumn{6}{|c|}{ Pathologically proven or probable CAA $(n=153)$} \\
\hline SAH absent & 4 & 108 & $3.7(1.0-9.5)$ & 1 (Ref) & 1 (Ref) \\
\hline SAH present & 36 & 371 & $9.7(6.8-13.4)$ & $2.6(0.9-7.2)$ & $2.1(0.7-6.2)$ \\
\hline \multicolumn{6}{|l|}{ Possible CAA $(n=108)$} \\
\hline SAH absent & 0 & 212 & 0 & 1 (Ref) & 1 (Ref) \\
\hline SAH present & 14 & 138.3 & $10.2(5.6-17.1)$ & $97.4(1.2-8,051.7)$ & NS \\
\hline
\end{tabular}

Abbreviations: $\mathrm{CAA}=$ cerebral amyloid angiopathy; $\mathrm{Cl}=$ confidence interval; $\mathrm{CSAH}=$ convexity subarachnoid hemorrhage; $\mathrm{cSS}=$ cortical superficial siderosis; $\mathrm{HR}$ = hazard ratio; $\mathrm{ICH}$ = intracerebral hemorrhage; NS = not significant; Ref = referent; $\mathrm{SAH}$ = subarachnoid hemorrhage.

${ }^{a}$ Adjusted for age, previous symptomatic ICH, presence of lobar cerebral microbleeds, and cSS in the whole ICH cohort and in the subgroup of patients with pathologically proven or probable CAA. Adjusted for age in the subgroup of patients with possible CAA.

(which has been thought to reflect ICH extension into the subarachnoid space) seems to be as strong a predictor of recurrent $\mathrm{ICH}$ as cSAH remote from $\mathrm{ICH}$. Detection of cSAH in the acute setting may therefore be useful for clinicians to stratify the risk of $\mathrm{ICH}$ recurrence in patients with acute lobar $\mathrm{ICH}$ and might be explored as an outcome marker in future clinical trials.

In our cohort of patients with CAA-related acute lobar ICH, the prevalence of $\mathrm{CSAH}$ was high, particularly in those with pathologically proven or probable CAA (78\%). These results are in line with recent studies that highlighted cSAH associated with lobar ICH as a neuroimaging marker suggestive of underlying CAA. In a CT-based study of patients with lobar ICH who died and had a research autopsy, the presence of $\mathrm{cSAH}$ was associated with moderate or severe CAA and is now included in the Edinburgh criteria for CAA. ${ }^{13}$ Similarly, in an MRI-based study of lobar ICH survivors, the presence of $\mathrm{cSAH}$ was associated with the diagnosis of probable CAA based on the modified Boston criteria. ${ }^{14}$

Our findings show that cSAH detected in patients with CAA$\mathrm{ICH}$ was independently associated with cSS. This association has previously been reported in patients with CAA with isolated (i.e., without associated ICH) cSAH, a less common presentation of CAA characterized by transient focal neurologic episodes. ${ }^{26,27}$ Experimental studies ${ }^{19}$ and longitudinal imaging studies ${ }^{28}$ have shown that repeated bleeding in the subarachnoid space can lead to cSS. In patients with acute $\mathrm{CAA}-\mathrm{ICH}$, expansion from parenchymal hemorrhage into the subarachnoid space is the most commonly advanced mechanism to explain cSAH. However, a few studies suggest that the primary hemorrhage sometimes occurs in the subarachnoid space in patients with CAA-ICH. ${ }^{28,29}$ Hence, cSAH might represent an early stage in the pathway leading from the rupture of leptomeningeal vessels to $\mathrm{cSS}^{30,31}$ and may reflect vascular fragility, heralding an increased risk of future $\mathrm{ICH}$ in patients with CAA.

A few small studies have suggested that the risk of future $\mathrm{ICH}$ is high after isolated cSAH in patients with CAA. ${ }^{29,30,32,33}$ However, the relationship between $\mathrm{CSAH}$ associated with lobar ICH and the risk of ICH recurrence remains unknown. In our prospective cohort study of CAA-ICH survivors with long-term follow-up, cSAH associated with lobar ICH was a strong predictor of recurrent $\mathrm{ICH}$, after adjustment for other potential predictors, including cSS, history of symptomatic $\mathrm{ICH}$, and lobar CMB. In line with previous studies, cSS was also an independent predictor of ICH recurrence. ${ }^{9,11,16,34}$ Both cSAH adjacent to $\mathrm{ICH}$ and remote $\mathrm{CSAH}$ were predictors of recurrent ICH. Although previous studies suggested that the presence of $\mathrm{cSAH}$ remote from ICH increased the risk of recurrent $\mathrm{ICH}, \mathrm{cSAH}$ connected to acute $\mathrm{ICH}$ was considered an extension of lobar hematoma into the subarachnoid space and had not previously been associated with an increased risk of future ICH.

Our study has limitations. The sample size is relatively small, and the number of recurrent ICHs is limited. Hence, CIs are wide and should be cautiously interpreted. The MRI-based 


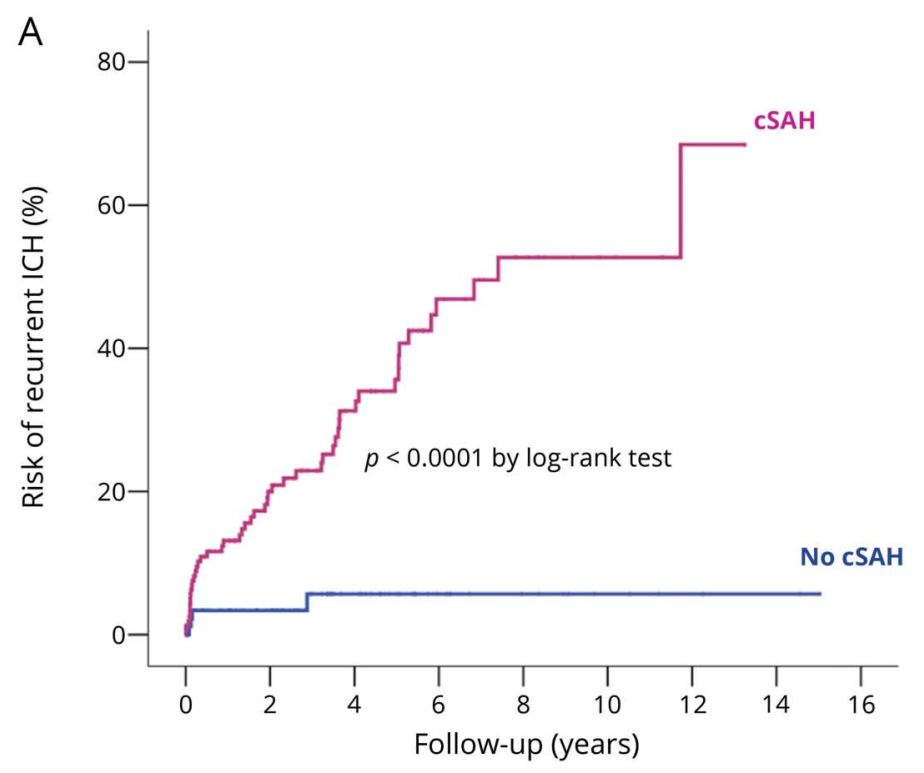

Patients at risk:

$\begin{array}{lcccccccc}\text { No cSAH } & 95 & 61 & 30 & 14 & 9 & 5 & 3 & 2 \\ \text { CSAH } & 166 & 87 & 52 & 24 & 13 & 6 & 2 & 0\end{array}$

B

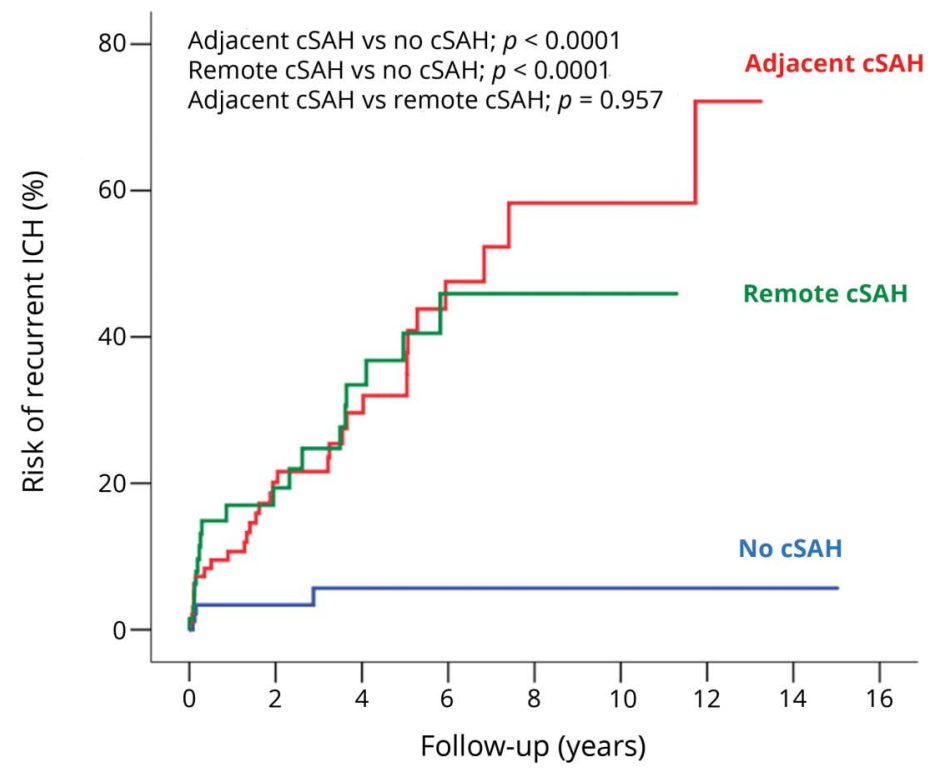

Patients at risk:

$\begin{array}{lllllllll}\text { No cSAH } & 95 & 61 & 30 & 14 & 9 & 5 & 3 & 2 \\ \text { Adjacent CSAH } & 98 & 54 & 31 & 14 & 7 & 3 & 2 & 0 \\ \text { Remote CSAH } & 68 & 33 & 21 & 10 & 6 & 3 & 0 & 0\end{array}$

Kaplan-Meier analyses showing time to recurrent symptomatic intracerebral hemorrhage $(\mathrm{ICH})$ according to the $(\mathrm{A})$ presence and (B) extent of convexity subarachnoid hemorrhage (cSAH) on baseline MRI in patients with cerebral amyloid angiopathyrelated $\mathrm{ICH}$. Testing of significance by the log-rank test. design of our study may have led to a selection bias toward the less severe ICH cases. However, the median ICH volume of our cohort $(20 \mathrm{~mL})$ was larger than in the Antihypertensive Treatment of Acute Cerebral Hemorrhage-II (ATACH-II) $)^{35}$ and Intensive Blood Pressure Reduction in Acute Cerebral
Hemorrhage Trial-II (INTERACT-II) ${ }^{36}$ trials. Whether our findings are generalizable to patients with $\mathrm{ICH}$ with $\mathrm{CT}$ evidence of cSAH remains to be evaluated in future works. In addition, our cohort was restricted to ICH survivors at discharge. Our results are not therefore generalizable to all 
Table 4 Multivariable Cox regression analyses of predictors of recurrent ICH in survivors of CAA-ICH

\begin{tabular}{lccc}
\hline & HR & $95 \% \mathrm{Cl}$ & $\begin{array}{l}\boldsymbol{p} \\
\text { Value }\end{array}$ \\
\hline Model 1 & & & \\
\hline cSAH presence & 7.47 & $2.64-21.13$ & $<0.001$ \\
\hline cSS presence & 1.87 & $1.00-3.52$ & 0.051 \\
\hline Age (per each 1-y increase) & 1.02 & $0.98-1.05$ & 0.352 \\
\hline $\begin{array}{l}\text { Previous symptomatic ICH (other } \\
\text { than index ICH) }\end{array}$ & 2.09 & $0.99-4.41$ & 0.053 \\
\hline Presence of lobar CMBs & & & \\
\hline
\end{tabular}

Model 2

\begin{tabular}{|c|c|c|c|}
\hline \multicolumn{4}{|l|}{ cSAH extent (no cSAH as reference) } \\
\hline cSAH adjacent to ICH & 7.87 & $2.71-22.85$ & $<0.001$ \\
\hline cSAH remote from ICH & 6.92 & $2.30-20.79$ & 0.001 \\
\hline cSS presence & 1.86 & $0.99-3.50$ & 0.055 \\
\hline Age (per each 1-y increase) & 1.02 & $0.98-1.05$ & 0.365 \\
\hline $\begin{array}{l}\text { Previous symptomatic ICH (other } \\
\text { than index ICH) }\end{array}$ & 2.16 & $1.00-4.62$ & 0.049 \\
\hline Presence of lobar CMBs & 0.59 & $0.32-1.09$ & 0.093 \\
\hline \multicolumn{4}{|c|}{$\begin{array}{l}\text { Abbreviations: } \mathrm{CAA}=\text { cerebral amyloid angiopathy; } \mathrm{Cl}=\text { confidence interval; } \\
\mathrm{CMB}=\text { cerebral microbleed; } \mathrm{CSAH}=\text { subarachnoid hemorrhage; } \mathrm{CSS}=\text { cortical } \\
\text { superficial siderosis; } \mathrm{HR}=\text { hazard ratio; ICH = intracerebral hemorrhage. } \\
\text { In sensitivity analyses, the Cox regression models remain consistent if CAA } \\
\text { diagnosis category (pathologically proven or probable CAA vs possible CAA) } \\
\text { is included. }\end{array}$} \\
\hline
\end{tabular}

patients with CAA with acute ICH. In a clinical setting, MRIs were not all acquired with identical sequence parameters, which may have affected our detection of imaging markers of small vessel disease. Nonetheless, our analysis did not find differences in rates of cSAH, cSS, and CMB according to the blood-sensitive sequences used (T2*-GRE vs SWI). In addition, because APOE genotype was available in $146(56 \%)$ of the patients, our predictive model was not fully adjusted for this potential predictor of ICH recurrence. Misclassification between acute cSAH and cSS, another hemorrhagic predictor, might have influenced our results. However, we used prespecified criteria (in particular the presence of hyperintense signal on FLAIR) based on current recommended guidelines ${ }^{18}$ to discriminate cSAH from cSS, and we identified $\mathrm{cSAH}$ as a predictor of recurrent ICH after adjusting for cSS. Finally, because detection of acute cSAH likely reduces over time, our results can be applied only to CAA-related lobar ICH survivors who have an MRI in the acute setting. Further work to establish the dynamic evolution and underlying mechanisms of our findings will be important.

Our findings suggest that in lobar ICH survivors, the presence of cSAH (adjacent or remote from acute ICH) is not only an imaging marker suggesting underlying CAA but also a strong predictor of recurrent $\mathrm{ICH}$ with important prognostic relevance. Because cSAH can be detected with MRI but also with $\mathrm{CT}$, this prognostic marker could be widely used in clinical practice, even when MRI is unavailable. Future research is required to externally validate these findings and to evaluate their clinical use.

\section{Study funding}

This study was supported by the following NIH grants: R01AG047975, R01AG026484, P50AG005134, K23AG028726, K23 NS083711, and R01 NS070834. Nicolas Raposo was supported by a Fulbright Scholarship and received an Arthur Sachs Scholarship from the Harvard University Committee on General Scholarship and a Philippe Foundation research grant.

\section{Disclosure}

The authors report no disclosures relevant to the manuscript. Go to Neurology.org/ $\mathrm{N}$ for full disclosures.

\section{Publication history}

Received by Neurology April 29, 2019. Accepted in final form September 25, 2019.

\section{Appendix Authors}

\begin{tabular}{|c|c|c|c|}
\hline Name & Location & Role & Contribution \\
\hline Nicolas Raposo, MD & $\begin{array}{l}\text { Stroke Research } \\
\text { Center, } \\
\text { Massachusetts } \\
\text { General Hospital, } \\
\text { Boston }\end{array}$ & Author & $\begin{array}{l}\text { Design and } \\
\text { conceptualized } \\
\text { study; collected } \\
\text { the data; analyzed } \\
\text { and interpreted } \\
\text { the data; } \\
\text { conducted } \\
\text { statistical } \\
\text { analyses; wrote } \\
\text { the manuscript; } \\
\text { prepared the } \\
\text { figures and tables; } \\
\text { revised the } \\
\text { manuscript }\end{array}$ \\
\hline $\begin{array}{l}\text { Andreas } \\
\text { Charidimou, MD, } \\
\text { PhD }\end{array}$ & $\begin{array}{l}\text { Stroke Research } \\
\text { Center, } \\
\text { Massachusetts } \\
\text { General Hospital, } \\
\text { Boston }\end{array}$ & Author & $\begin{array}{l}\text { Collected the } \\
\text { data; analyzed } \\
\text { and interpreted } \\
\text { the data; revised } \\
\text { the manuscript }\end{array}$ \\
\hline $\begin{array}{l}\text { Duangnapa } \\
\text { Roongpiboonsopit, } \\
\text { MD, MSc }\end{array}$ & $\begin{array}{l}\text { Division of } \\
\text { Neurology, } \\
\text { Faculty of } \\
\text { Medicine, } \\
\text { Department of } \\
\text { Medicine, } \\
\text { Naresuan } \\
\text { University, } \\
\text { Phitsanulok, } \\
\text { Thailand }\end{array}$ & Author & $\begin{array}{l}\text { Collected the } \\
\text { data; analyzed } \\
\text { and interpreted } \\
\text { the data; revised } \\
\text { the manuscript }\end{array}$ \\
\hline Michelle Onyekaba & $\begin{array}{l}\text { Stroke Research } \\
\text { Center, } \\
\text { Massachusetts } \\
\text { General Hospital, } \\
\text { Boston }\end{array}$ & Author & $\begin{array}{l}\text { Collected the } \\
\text { data; analyzed } \\
\text { and interpreted } \\
\text { the data; revised } \\
\text { the manuscript }\end{array}$ \\
\hline M. Edip Gurol, MD & $\begin{array}{l}\text { Stroke Research } \\
\text { Center, } \\
\text { Massachusetts } \\
\text { General Hospital, } \\
\text { Boston }\end{array}$ & Author & $\begin{array}{l}\text { Revised the } \\
\text { manuscript }\end{array}$ \\
\hline
\end{tabular}


Appendix (continued)

\begin{tabular}{|c|c|c|c|}
\hline Name & Location & Role & Contribution \\
\hline $\begin{array}{l}\text { Jonathan Rosand, } \\
\text { MD, MSc }\end{array}$ & $\begin{array}{l}\text { Division of } \\
\text { Neurocritical } \\
\text { Care and } \\
\text { Emergency } \\
\text { Neurology, } \\
\text { Massachusetts } \\
\text { General Hospital, } \\
\text { Harvard Medical } \\
\text { School, Boston }\end{array}$ & Author & $\begin{array}{l}\text { Revised the } \\
\text { manuscript }\end{array}$ \\
\hline $\begin{array}{l}\text { Steven M. } \\
\text { Greenberg, MD, } \\
\text { PhD }\end{array}$ & $\begin{array}{l}\text { Stroke Research } \\
\text { Center, } \\
\text { Massachusetts } \\
\text { General Hospital, } \\
\text { Boston }\end{array}$ & Author & $\begin{array}{l}\text { Funding, data } \\
\text { collection; revised } \\
\text { the manuscript }\end{array}$ \\
\hline $\begin{array}{l}\text { Joshua N. } \\
\text { Goldstein, MD, PhD }\end{array}$ & $\begin{array}{l}\text { Division of } \\
\text { Neurocritical } \\
\text { Care and } \\
\text { Emergency } \\
\text { Neurology, } \\
\text { Massachusetts } \\
\text { General Hospital, } \\
\text { Harvard Medical } \\
\text { School, Boston }\end{array}$ & Author & $\begin{array}{l}\text { Revised the } \\
\text { manuscript }\end{array}$ \\
\hline $\begin{array}{l}\text { Anand } \\
\text { Viswanathan, MD, } \\
\text { PhD }\end{array}$ & $\begin{array}{l}\text { Stroke Research } \\
\text { Center, } \\
\text { Massachusetts } \\
\text { General Hospital, } \\
\text { Boston }\end{array}$ & Author & $\begin{array}{l}\text { Design and } \\
\text { conceptualized } \\
\text { study; interpreted } \\
\text { the data; revised } \\
\text { the manuscript; } \\
\text { supervised the } \\
\text { study. }\end{array}$ \\
\hline
\end{tabular}

\section{References}

1. Charidimou A, Gang Q, Werring DJ. Sporadic cerebral amyloid angiopathy revisited: recent insights into pathophysiology and clinical spectrum. J Neurol Neurosurg Psychiatry 2012;83:124-137.

2. van Asch CJ, Luitse MJ, Rinkel GJ, van der Tweel I, Algra A, Klijn CJ. Incidence, case fatality, and functional outcome of intracerebral haemorrhage over time, according to age, sex, and ethnic origin: a systematic review and meta-analysis. Lancet Neurol 2010; 9:167-176.

3. Roquer J, Rodriguez-Campello A, Jimenez-Conde J, et al. Sex-related differences in primary intracerebral hemorrhage. Neurology 2016;87:257-262.

4. Moulin S, Labreuche J, Bombois S, et al. Dementia risk after spontaneous intracerebral haemorrhage: a prospective cohort study. Lancet Neurol 2016;15:820-829.

5. Planton M, Saint-Aubert L, Raposo N, et al. High prevalence of cognitive impairment after intracerebral hemorrhage. PLoS One 2017;12:e178886.

6. Arima H, Tzourio C, Anderson C, et al. Effects of perindopril-based lowering of blood pressure on intracerebral hemorrhage related to amyloid angiopathy: the PROGRESS trial. Stroke 2010;41:394-396.

7. Goldstein JN, Greenberg SM. Should anticoagulation be resumed after intracerebral hemorrhage? Cleve Clin J Med 2010;77:791-799.

8. Viswanathan A, Rakich SM, Engel C, et al. Antiplatelet use after intracerebral hemorrhage. Neurology 2006;66:206-209.

9. Roongpiboonsopit D, Charidimou A, William CM, et al. Cortical superficial siderosis predicts early recurrent lobar hemorrhage. Neurology 2016;87:1863-1870.

10. Charidimou A, Boulouis G, Roongpiboonsopit D, et al. Cortical superficial siderosis multifocality in cerebral amyloid angiopathy: a prospective study. Neurology 2017;89: $2128-2135$.
11. Wollenweber FA, Opherk C, Zedde M, et al. Prognostic relevance of cortical superficial siderosis in cerebral amyloid angiopathy. Neurology 2019;92:e792-e801.

12. Samarasekera N, Rodrigues MA, Toh PS, Al-Shahi R. Imaging features of intracerebral hemorrhage with cerebral amyloid angiopathy: systematic review and meta-analysis. PLoS One 2017;12:e0180923.

13. Rodrigues MA, Samarasekera N, Lerpiniere C, et al. The Edinburgh CT and genetic diagnostic criteria for lobar intracerebral haemorrhage associated with cerebral amyloid angiopathy: model development and diagnostic test accuracy study. Lancet Neurol 2018;17:232-240.

14. Viguier A, Raposo N, Patsoura S, et al. Subarachnoid and subdural hemorrhages in lobar intracerebral hemorrhage associated with cerebral amyloid angiopathy. Stroke 2019;50:1567-1569.

15. Attems J. Sporadic cerebral amyloid angiopathy: pathology, clinical implications, and possible pathomechanisms. Acta Neuropathol 2005;110:345-359.

16. Charidimou A, Peeters AP, Jager R, et al. Cortical superficial siderosis and intracerebral hemorrhage risk in cerebral amyloid angiopathy. Neurology 2013;81: 1666-1673.

17. Charidimou A, Boulouis G, Xiong L, et al. Cortical superficial siderosis and first-ever cerebral hemorrhage in cerebral amyloid angiopathy. Neurology 2017;88:1607-1614

18. Charidimou A, Linn J, Vernooij MW, et al. Cortical superficial siderosis: detection and clinical significance in cerebral amyloid angiopathy and related conditions. Brain 2015;138:2126-2139.

19. Koeppen AH, Dickson AC, Chu RC, Thach RE. The pathogenesis of superficial siderosis of the central nervous system. Ann Neurol 1993;34:646-653.

20. O'Donnell HC, Rosand J, Knudsen KA, et al. Apolipoprotein E genotype and the risk of recurrent lobar intracerebral hemorrhage. N Engl J Med 2000;342:240-245.

21. Knudsen KA, Rosand J, Karluk D, Greenberg SM. Clinical diagnosis of cerebral amyloid angiopathy: validation of the Boston criteria. Neurology 2001;56:537-539.

22. Charidimou A, Boulouis G, Pasi M, et al. MRI-visible perivascular spaces in cerebral amyloid angiopathy and hypertensive arteriopathy. Neurology 2017;88:1157-1164.

23. Wardlaw JM, Smith EE, Biessels GJ, et al. Neuroimaging standards for research into small vessel disease and its contribution to ageing and neurodegeneration. Lancet Neurol 2013;12:822-838

24. Greenberg SM, Vernooij MW, Cordonnier C, et al. Cerebral microbleeds: a guide to detection and interpretation. Lancet Neurol 2009;8:165-174.

25. Fazekas F, Chawluk JB, Alavi A, Hurtig HI, Zimmerman RA. MR signal abnormalities at $1.5 \mathrm{~T}$ in Alzheimer's dementia and normal aging. AJR Am J Roentgenol 1987;149: 351-356.

26. Charidimou A, Boulouis G, Fotiadis P, et al. Acute convexity subarachnoid haemorrhage and cortical superficial siderosis in probable cerebral amyloid angiopathy without lobar haemorrhage. J Neurol Neurosurg Psychiatry 2018;89:397-403.

27. Raposo N, Calviere L, Cazzola V, et al. Cortical superficial siderosis and acute convexity subarachnoid hemorrhage in cerebral amyloid angiopathy. Eur J Neurol 2018; 25:253-259.

28. Beitzke M, Enzinger C, Wunsch G, Asslaber M, Gattringer T, Fazekas F. Contribution of convexal subarachnoid hemorrhage to disease progression in cerebral amyloid angiopathy. Stroke 2015;46:1533-1540.

29. Takeda S, Yamazaki K, Miyakawa T, et al. Subcortical hematoma caused by cerebral amyloid angiopathy: does the first evidence of hemorrhage occur in the subarachnoid space? Neuropathology 2003;23:254-261.

30. Calviere L, Cuvinciuc V, Raposo N, et al. Acute convexity subarachnoid hemorrhage related to cerebral amyloid angiopathy: clinicoradiological features and outcome. J Stroke Cerebrovasc Dis 2016;25:1009-1016.

31. Ni J, Auriel E, Jindal J, et al. The characteristics of superficial siderosis and convexity subarachnoid hemorrhage and clinical relevance in suspected cerebral amyloid angiopathy. Cerebrovasc Dis 2015;39:278-286.

32. Wilson D, Hostettler IC, Ambler G, Banerjee G, Jager HR, Werring DJ. Convexity subarachnoid haemorrhage has a high risk of intracerebral haemorrhage in suspected cerebral amyloid angiopathy. J Neurol 2017;264:664-673.

33. Martinez-Lizana E, Carmona-Iragui M, Alcolea D, et al. Cerebral amyloid angiopathyrelated atraumatic convexal subarachnoid hemorrhage: an ARIA before the tsunami. J Cereb Blood Flow Metab 2015;35:710-717.

34. Moulin S, Casolla B, Kuchcinski G, et al. Cortical superficial siderosis: a prospective observational cohort study. Neurology 2018;91:e132-e138.

35. Qureshi AI, Palesch YY, Barsan WG, et al. Intensive blood-pressure lowering in patients with acute cerebral hemorrhage. N Engl J Med 2016;375:1033-1043.

36. Anderson CS, Heeley E, Huang Y, et al. Rapid blood-pressure lowering in patients with acute intracerebral hemorrhage. N Engl J Med 2013;368:2355-2365. 